\title{
ENRIQUECIMENTO DO SISTEMA SOLO-SERAPILHEIRA COM ESPÉCIES ARBÓREAS APTAS PARA RECUPERAÇÃO DE ÁREAS DEGRADADAS ${ }^{1}$
}

\author{
Antonio Jorge Tourinho Braga ${ }^{2}$, James Jackson Griffith ${ }^{3}$, Haroldo Nogueira de Paiva ${ }^{3}$, Fabiana Cabral \\ da Silva ${ }^{2}$, Viviana Borges Corte ${ }^{2}$ e João Augusto Alves Meira Neto ${ }^{4}$
}

\begin{abstract}
RESUMO - Este estudo teve como objetivo avaliar o comportamento do enriquecimento no sistema solo orgânico-serapilheira, com sementes de espécies arbóreas nativas, para revegetação de áreas degradadas. O trabalho foi conduzido em casa de sombra e em bancadas a pleno sol, no Viveiro de Pesquisas do Departamento de Engenharia Florestal, situado no Campus da Universidade Federal de Viçosa (UFV). No levantamento do banco de sementes, foram encontrados 508 indivíduos, dos quais foram identificadas 38 espécies, pertencentes a 34 gêneros e distribuídas em 22 famílias. As avaliações da germinação das sementes introduzidas e do banco de sementes indicaram não haver diferença entre os ambientes testados (sombreado e a pleno sol). $\mathrm{O}$ crescimento das mudas, tanto das espécies provenientes dos propágulos contidos na serapilheira e no solo orgânico quanto das espécies utilizadas no enriquecimento, foi maior no ambiente sombreado. Os solos não adubados tiveram maior porcentual de sementes germinadas em relação aos solos adubados. A adubação dos substratos foi fundamental para o crescimento das mudas. Os resultados, portanto, demonstraram a eficiência do enriquecimento do banco de sementes e confirmaram o potencial dessa técnica para revegetação de áreas degradadas.
\end{abstract}

Palavras-chave: Serapilheira, banco de sementes e revegetação de áreas degradadas.

\section{LITTER-SOIL SYSTEM ENRICHMENT WITH TREE SPECIES SUITABLE FOR DISTURBED LAND RECLAMATION}

\begin{abstract}
This study evaluated the behavior of an organic soil-litter system seeded with native species with implications for revegetation of disturbed lands. The experiment was carried out in a greenhouse and on benches exposed to open sunlight at the Research Nursery of the Department of Forestry of the Universidade Federal de Vicosa (UFV). The inventory identified 508 individuals, out of which 38 species were identified, belonging to 34 genera and distributed among 22 families. Evaluation of both introduced seeds and seed bank did not show any differences in germination for the environmental regimes tested. Seedling growth for species originating from litter and topsoil propagules and for species inserted for enrichment was greater under shade. Unfertilized soils had a higher percentage of germinated seeds than fertilized soils. Fertilization was shown to be fundamental for seedling growth. Hence, results demonstrate improved efficiency by enriching a seed bank and confirm the potential of this technique for revegetation of disturbed lands.
\end{abstract}

Keywords: Forest litter, seed bank and revegetation.

\footnotetext{
${ }^{1}$ Recebido em 22.11.2006 e aceito para publicação em 22.06.2007.

${ }^{2}$ Programa de Pós-Graduação em Ciência Florestal da Universidade Federal de Viçosa (UFV). E-mail: <tourinhobraga@ yahoo.com.br>.

${ }^{3}$ Departamento de Engenharia Florestal da UFV. E-mail: <griffith@ufv.br>.

${ }^{4}$ Departamento de Biologia Vegetal da UFV. E-mail: <j.meira@ufv.br>.
} 


\section{INTRODUÇÃO}

A serapilheira é formada pelo material solto encontrado no solo da floresta, que contém sementes de plantas herbáceas, arbustivas e arbóreas. Esse material protege a superfície do solo dos raios solares mantendo a umidade, o que, conseqüentemente, cria condições favoráveis para o desenvolvimento das plantas e da fauna nele contidas, sendo ideal para ser empregado na revegetação de áreas degradadas (IBAMA, 1990). Além disso, sua produção e decomposição são utilizadas como indicadores de restauração em projetos de recuperação de áreas degradadas (ARATO et al., 2003).

A utilização da serapilheira na recuperação de tais áreas proporciona a germinação de sementes pioneiras e secundárias iniciais dormentes presentes no banco de sementes que compõe essa área. (FERREIRA et al., 1997). Durante o processo de recuperação de áreas degradadas, a dinâmica das comunidades vegetais pode ser manipulada visando melhorar o estabelecimento de espécies, acelerar o ritmo da sucessão e aumentar a diversidade biológica. Entretanto, o sucesso inicial da recuperação das áreas degradadas depende do suprimento adequado de propágulos (sementes e estruturas vegetativas), bem como de um bom entendimento dos mecanismos relacionados ao processo de sucessão da comunidade vegetal (REDENTE et al., 1993).

No sentido de otimizar a técnica de revegetação com serapilheira e, com isso, acelerar o processo sucessional em áreas degradadas, este estudo teve como objetivo avaliar o comportamento do enriquecimento no sistema solo orgânico-serapilheira, utilizando sementes de Caesalpinia peltophoroides Benth (sibipiruna), Dalbergia nigra (Vell.) Allemao ex Benth (jacarandá-da-baía), Tabebuia serratifolia (Vahl) Nicholson (ipê-amarelo) e Zeyheria tuberculosa (Vell.) Bur. (ipê-preto).

\section{MATERIAL E MÉTODOS}

O estudo foi realizado com serapilheira coletada da "Mata da Garagem", situada no Campus da Universidade Federal de Viçosa (UFV), com cerca de 50 ha, no Município de Viçosa, Minas Gerais, localizado nas coordenadas $20^{\circ} 45^{\prime} \mathrm{S}$ e $42^{\circ} 55^{\prime} \mathrm{W}$. O fragmento florestal que abrange a área de coleta tem mais de 40 anos de regeneração natural, após corte raso da cobertura original para plantio de café, sendo caracterizado como Floresta Estacional Semidecidual (SILVA et al., 1999). O clima da região, segundo Köppen, é do tipo Cwb, mesotérmico, com verões chuvosos, invernos frios e secos. A precipitação média nos últimos 30 anos foi de cerca de $1.221 \mathrm{~mm}$. A região é definida por uma estação seca e outra chuvosa (MARANGON et al., 2003).

A serapilheira e o solo foram coletados em locais representativos do estágio médio de sucessão secundária da Mata, em pontos distribuídos ao acaso, totalizando 20 amostras coletadas, cada uma composta de quatro subamostras. Para isso, foram utilizados gabaritos quadrados de madeira de 0,25x0,25 m (0,0625 $\left.\mathrm{m}^{2}\right)$, colocados sobre a superfície do solo, de onde foi retirada primeiramente a serapilheira e, em seguida, o solo sob ela, com pá de lixo, até uma profundidade de $5 \mathrm{~cm}$. O material coletado foi colocado em sacos plásticos de $30 \mathrm{~L}$ e transportados, em seguida, para o Viveiro de Pesquisas do Departamento de Engenharia Florestal da UFV, onde ocorreu a instalação do experimento.

Para a montagem do experimento no viveiro, foram utilizadas 40 caixas de madeira no formato de $50 \times 50$ $\mathrm{x} 15 \mathrm{~cm}$. Um total de 20 dessas caixas receberam uma camada de $3 \mathrm{~cm}$ de substrato e, em seguida, foram enchidas com o solo orgânico coletado na floresta. As 20 caixas restantes foram preenchidas apenas com terra de subsolo, que serviu como substrato, sendo essa terra tratada com brometo de metila por $72 \mathrm{~h}$ e colocada para ventilar por $48 \mathrm{~h}$. A adubação foi realizada conforme recomendações para a produção de mudas em viveiro (GONÇALVES, 1995). Foram adubadas 10 caixas que continham o subsolo e outras $10 \mathrm{com}$ o solo orgânico. As análises física e química dos solos orgânicos coletados da floresta e do subsolo de barranco utilizados como substratos foram realizadas no Laboratório de Análise de Solos do Departamento de Solos da Universidade Federal de Viçosa (Tabela 1).

Após $48 \mathrm{~h}$ da adubação, foram semeadas 80 sementes por caixa (subparcelas), sendo 20 de cada espécie, totalizando 1.600 sementes por ambiente (parcelas). As sementes de sibipiruna ( $C$. peltophoroides), jacarandá-da-baía (D. nigra), ipêamarelo (T. serratifolia) e ipê-preto (Z. tuberculosa) foram postas para germinar, de forma aleatória, em pequenas covas feitas nas subparcelas que continham a terra de subsolo como substrato. Em seguida, as covas contendo as sementes foram cobertas por uma fina camada do subsolo. Nas subparcelas preenchidas com o solo orgânico, foi realizado o enriquecimento, semeandose as sementes diretamente sobre o solo, sendo, em seguida, cobertas com a serapilheira. 
Tabela 1 - Características física e química do solo orgânico da "Mata da Garagem", situada no Campus da Universidade Federal de Viçosa (UFV), Minas Gerais, e do subsolo de barranco

Table 1 - Chemical and physical characteristics of organic soil from "Mata da Garagem", located at the Universidade Federal de Vicosa, and of embankment subsoil

\begin{tabular}{|c|c|c|c|c|c|c|c|c|}
\hline \multirow[t]{2}{*}{ Solo } & $\mathrm{pH}$ & $\mathrm{P}$ & K & $\mathrm{Na}$ & $\mathrm{Ca}^{2+}$ & $\mathrm{Mg}^{2+}$ & $\mathrm{Al}^{3+}$ & $\mathrm{H}+\mathrm{Al}$ \\
\hline & $\mathrm{H}_{2} \mathrm{O}$ & & $\mathrm{mg} / \mathrm{dm}$ & & & \multicolumn{3}{|c|}{$\mathrm{cmol}_{\mathrm{c}} / \mathrm{dm}^{3}$} \\
\hline Solo orgânico & 3,5 & 0,9 & 29 & - & 0,1 & 0,2 & 2,17 & 9,1 \\
\hline Subsolo & 4,6 & 0,4 & 5 & - & 0 & 0 & 0,82 & 5,6 \\
\hline \multirow[t]{2}{*}{ Solo } & SB & $(\mathrm{t})$ & $(\mathrm{T})$ & $\mathrm{V}$ & $\mathrm{m}$ & ISNa & $\mathrm{MO}$ & $\mathrm{P}-\mathrm{rem}$ \\
\hline & \multicolumn{3}{|c|}{$\mathrm{cmol}_{\mathrm{c}} / \mathrm{dm}^{3}$} & \multicolumn{3}{|c|}{$\%$} & dag/kg & $\mathrm{mg} / \mathrm{L}$ \\
\hline Solo orgânico & 0,3 & 2,5 & 9,4 & 3,6 & 87 & - & 6,27 & 29,6 \\
\hline Subsolo & 0 & 0,9 & 5,6 & 0,5 & 97 & - & 3,33 & 13,8 \\
\hline \multicolumn{4}{|c|}{$\begin{array}{l}\text { pH em água, } \mathrm{KCl} \text { e } \mathrm{CaCl} \text { - Relação } 1: 2,5 \\
\mathrm{P}-\mathrm{Na}-\mathrm{K}-\mathrm{Fe}-\mathrm{Zn}-\mathrm{Mn}-\mathrm{Cu}-\mathrm{Extratos} \mathrm{Mehlich} 1 \\
\mathrm{Ca}-\mathrm{Mg}-\mathrm{Al}-\text { Extrator: } \mathrm{KCl}-1 \mathrm{~mol} / \mathrm{L} \\
\mathrm{H}+\mathrm{A} 1-\text { Extrator Acetato de Cálcio } 0,5 \mathrm{~mol} / \mathrm{L}-\mathrm{pH} 7,0\end{array}$} & \multicolumn{5}{|c|}{$\begin{array}{l}\text { CTC }(\mathrm{t}) \text { - Capacidade de Troca Catiônica Efetiva } \\
\text { CTC }(\mathrm{t}) \text { - Capacidade de Troca Catiônica a pH 7,0 } \\
\text { V = Índice de Saturação de Bases } \\
\text { m = Índice de Saturação de Alumínio }\end{array}$} \\
\hline
\end{tabular}

A metade das 40 caixas foi distribuída em bancadas, dentro da casa de sombra, sob $60 \%$ de sombreamento (ambiente 1), sendo a outra metade distribuída em bancadas a pleno sol (ambiente 2). Durante a condução do experimento, a irrigação foi realizada levando-se em consideração as condições climáticas do dia, de forma a evitar o estresse hídrico.

O delineamento experimental utilizado foi em blocos casualizados no esquema de parcelas subdivididas, com oito tratamentos e cinco repetições, sendo os ambientes as parcelas e os solos, as subparcelas. Foram analisados os seguintes tratamentos:

T1 - solo orgânico não adubado mais serapilheira, sob $60 \%$ de sombreamento.

T2 - solo orgânico adubado mais serapilheira, sob $60 \%$ de sombreamento.

T3 - subsolo não-adubado, sob $60 \%$ de sombreamento.

T4 - subsolo adubado, sob $60 \%$ de sombreamento.

T5 - solo orgânico não-adubado mais serapilheira, a pleno sol.

T6 - solo orgânico adubado mais serapilheira, a pleno sol.

T7 - subsolo não-adubado, a pleno sol.

T8 - subsolo adubado, a pleno sol.

Para avaliar a qualidade das sementes e estas servirem de testemunhas, foram conduzidos, no Laboratório de Análise de Sementes Florestais do Departamento de Engenharia Florestal da UFV, os testes de porcentagem de germinação e freqüência relativa de germinação (LABOURIAU e VALADARES, 1976; LABOURIAU, 1983).

A contagem de germinação foi realizada no encerramento do experimento. Foram consideradas germinadas as sementes que originaram mudas normais, com todas as estruturas essenciais, sendo os resultados expressos em porcentagem. Após 90 dias da semeadura, as mudas foram avaliadas em altura $(\mathrm{H})$; diâmetro do coleto (D); relação H/D; biomassa seca da parte aérea (BSPA), da raiz (BSR), total (BST) e relação parte aérea sobre raiz (RPA/R); e, nas espécies de ipê-amarelo e ipê-preto, foram avaliadas a área foliar (AF) e a razão área foliar sobre massa seca total (RAF).

Foram identificados e quantificados todos os indivíduos que emergiram do banco de sementes, presente na serapilheira e no solo orgânico. Para apresentação das espécies, considerou-se a classificação de Cronquist (1981), com exceção das famílias Caesalpiniaceae, Fabaceae e Mimosaceae, que foram tratadas como subfamília de Leguminosae.

Os dados de todos os parâmetros foram submetidos à análise de variância e as médias, comparadas pelo teste de Tukey a $5 \%$ de probabilidade, usando-se o programa SISVAR (FERREIRA, 2000).

\section{RESULTADOS E DISCUSSÃO}

\subsection{Avaliação do banco de sementes}

Ao final de três meses, os indivíduos germinantes do banco de sementes apresentaram um total de 38 espécies, distribuídas em 34 gêneros e 22 famílias (Tabela 2). Dos 508 indivíduos, 291 exemplares foram identificados como indivíduos arbóreos (57,3\%) e 217

R. Árvore, Viçosa-MG, v.31, n.6, p.1145-1154, 2007 
herbáceos (42,7\%). A quantidade de indivíduos herbáceos, portanto, não superou a de indivíduos arbóreos, como ocorreu em outros trabalhos realizados com banco de sementes (LEAL FILHO, 1992; OZÓRIO, 2000; FRANCO, 2005; GASPARINO et al., 2006; SOUZA et al., 2006).
Tanto as médias de altura e da relação entre a biomassa seca de parte aérea e de raiz dos indivíduos arbóreos quanto às médias de biomassa seca de raiz, total e da relação da parte aérea e de raiz dos indivíduos herbáceos não variaram entre os ambientes e os solos testados (Tabela 3).

Tabela 2 - Relação das espécies arbóreas e herbáceas originadas do banco de sementes da Mata da Garagem. CS = Categoria Sucessional; SI = Secundária Inicial; ST = Secundária Tardia; H = Herbácea; NC = Não Classificada; PI = Pioneira; $\mathrm{CV}=$ Ciclo de Vida; $\mathrm{A}=$ Anual; e $\mathrm{P}=$ Perene

Table 2 - Tree and herbaceous species originating from "Mata da Garagem". SC = Succession Category; IS = Initial Secondary; $L S=$ Late Secondary; $H=$ Herbaceous $; N C=$ Not Classified $; P I=$ Pioneer $;$ LC $=$ Life Cycle $; A=A n n u a l ; P=$ Perennial

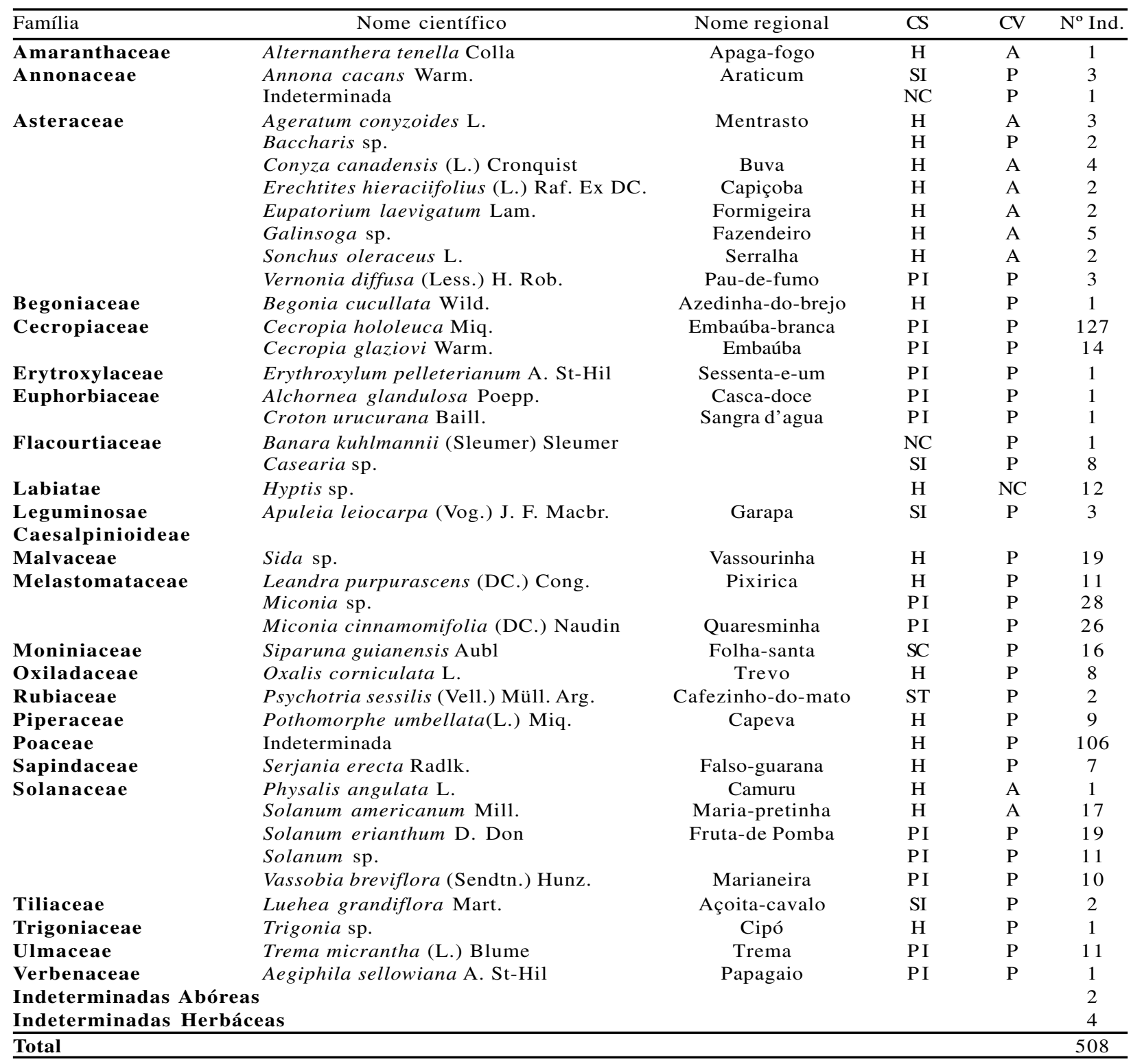

R. Árvore, Viçosa-MG, v.31, n.6, p.1145-1154, 2007 
Tabela 3 - Altura (H), diâmetro do coleto (D), relação altura/diâmetro do coleto (RH/D), peso de biomassa seca da parte aérea (BSPA), da raiz (BSR), total (BST) e da relação da parte aérea/raiz (RPA/R) das mudas arbóreas e herbáceas originadas do banco de sementes nos diferentes ambientes e solos testados, após 90 dias

Table 3 - Height $(H)$, diameter $(D)$, ratio between diameter/height (RH/D), shoot dry biomass (BSPA), root biomass (BSR), total dry biomass $(B S T)$ and ratio between root and shoot $(R P A / R)$ of the tree seedlings and herbaceous species originating from litter and topsoil seed bank, after 90 days

\begin{tabular}{|c|c|c|c|c|c|c|c|}
\hline & \multicolumn{7}{|c|}{ Arbóreas } \\
\hline Ambiente & $\mathrm{H}$ & $\mathrm{D}$ & $\mathrm{RH} / \mathrm{D}$ & BSPA & BSR & BST & RPA/R \\
\hline 1 & $5,15 a$ & $1,64 a$ & $3,01 b$ & $2,52 \mathrm{a}$ & $2,17 \mathrm{a}$ & $4,69 a$ & $1,27 \mathrm{a}$ \\
\hline 2 & $3,83 \mathrm{a}$ & $1,86 a$ & $2,06 \quad \mathrm{a}$ & $3,15 \mathrm{a}$ & $3,44 \mathrm{a}$ & $6,59 \mathrm{a}$ & $1,17 \mathrm{a}$ \\
\hline \multicolumn{8}{|l|}{ Solo } \\
\hline 1 & $3,16 \mathrm{a}$ & $1,29 b$ & $2,54 \mathrm{a}$ & $1,02 b$ & $0,77 b$ & $1,80 \mathrm{~b}$ & $1,25 \mathrm{a}$ \\
\hline \multirow[t]{2}{*}{2} & $5,83 \mathrm{a}$ & $2,24 \quad \mathrm{a}$ & $2,53 \mathrm{a}$ & 4,66 a & 4,83 a & $9,49 \quad$ a & $1,19 \mathrm{a}$ \\
\hline & \multicolumn{7}{|c|}{ Herbáceas } \\
\hline Ambiente & $\mathrm{H}$ & $\mathrm{D}$ & RH/D & BSPA & BSR & BST & RPA/R \\
\hline 1 & 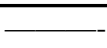 & $\longrightarrow$ & $\longrightarrow$ & $5,65 \mathrm{a}$ & $9,23 a$ & $14,88 \mathrm{a}$ & $1,88 \mathrm{a}$ \\
\hline 2 & - & - & - & $5,18 \mathrm{a}$ & $2,15 \mathrm{a}$ & $7,33 \mathrm{a}$ & $2,46 \mathrm{a}$ \\
\hline \multicolumn{8}{|l|}{ Solo } \\
\hline 1 & 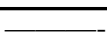 & - & 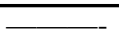 & $1,76 b$ & $1,23 \mathrm{a}$ & $2,99 a$ & $\overline{1,66 a}$ \\
\hline 2 & 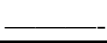 & - & - & 9,08 a & $10,15 \mathrm{a}$ & $19,23 \mathrm{a}$ & $2,69 \mathrm{a}$ \\
\hline
\end{tabular}

Médias seguidas pela mesma letra não diferem entre si, a 5\% de probabilidade, pelo teste de Tukey.

A adubação realizada no solo orgânico favoreceu o crescimento em diâmetro das mudas arbóreas. Os indivíduos dessas espécies cultivadas sombreadas apresentaram os maiores valores para a relação entre altura e diâmetro do coleto. A relação altura/diâmetro do coleto (RH/D) é um parâmetro que indica qualidade das mudas emergidas do banco de sementes, uma vez que se espera equilíbrio no desenvolvimento. Os valores da relação H/D indicaram que houve mais crescimento em altura do que em diâmetro nas plantas sombreadas.

As produções de biomassa seca da parte aérea, raiz e total foram maiores nas plantas arbóreas que cresceram no solo orgânico adubado, o que demonstra a eficiência da adubação para crescimento das mudas.

Pelos resultados, verifica-se que o ambiente sombreado estimulou o crescimento dos indivíduos arbóreos e herbáceos. Ficou constatado, ainda, que o solo orgânico adubado apresentou as melhores condições para o desenvolvimento das espécies nele germinadas.

\subsection{Germinação das sementes}

O teste de porcentagem de germinação, realizado no Laboratório de Sementes Florestais (DEF/UFV), para avaliar a viabilidade, demonstrou que a maior porcentagem de germinação ocorreu nas sementes de ipê-amarelo (90\%), seguida da dE ipê-preto (78\%), dE sibipiruna (73\%) e jacarandá-da-baía com $71 \%$.
O pico de germinação das sementes de ipê-amarelo ocorreu cinco dias depois de iniciado o teste, apresentando uma freqüência relativa de $47,78 \%$ e um acúmulo de sementes germinadas de $73 \%$. Nas sementes de ipê-preto, que apresentaram menor velocidade de germinação em relação às demais, verificou-se o pico de germinação no sétimo dia, com uma frequiência relativa de $24,36 \%$ e um acumulado de $53 \%$ das sementes germinadas. O pico de germinação das sementes de sibipiruna aconteceu também no sétimo dia, apresentando uma freqüência relativa de $35,62 \%$, com um acumulado de $66 \%$ das sementes germinadas até então. As sementes de jacarandáda-baía apresentaram pico de germinação nove dias depois de iniciada a avaliação, verificando-se uma freqüência relativa de $33,80 \%$ e um acumulado de $62 \%$ das sementes germinadas (Figura 1).

As sementes referentes ao tratamento-testemunha (teste de laboratório) apresentaram significativamente os maiores valores de porcentual de germinação, comparativamente aos tratamentos (Tabela 4), à exceção das sementes de ipê-preto, que tiveram maior porcentual de germinação no solo orgânico a pleno sol (T5), com 87\%, superando, portanto, o tratamentotestemunha (78\%). Esse fato pode estar associado ao microambiente formado pela cobertura de serapilheira e pela irradiação solar direta, o que favoreceu a germinação.

R. Árvore, Viçosa-MG, v.31, n.6, p.1145-1154, 2007 


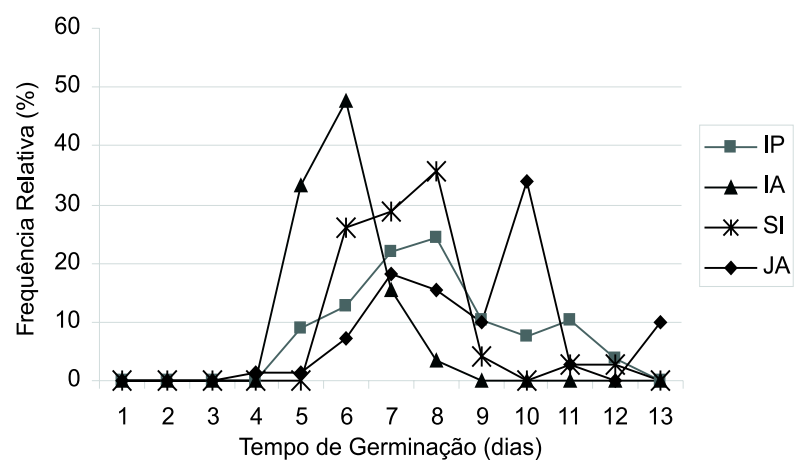

Figura 1 - Tempo de germinação, com os picos de germinação das sementes em testes de laboratório. IP = ipêpreto (Z. tuberculosa), IA $=$ ipê-amarelo $(T$. serratifolia), $\mathrm{SI}=$ sibipiruna $(C$. peltophoroides $)$; e JA = jacarandá-da-baía (D. nigra).

Figure 1 -Time of germination, with germination peaks detected in laboratory tests. $I P=$ "ipê-preto" (Z. tuberculosa), $I A=$ "ipe-amarelo" (T. serratifolia), SI = "sibipiruna" (C. peltophoroides) and JA = "jacarandá-da-baia (D. nigra).

As sementes de ipê-amarelo e de ipê-preto apresentaram maior porcentagem de germinação no solo orgânico não-adubado. O solo orgânico sem adubação a pleno sol foi o melhor tratamento (T5) para a germinação das sementes de ipê-preto. Quanto às sementes de sibipiruna e de jacarandá-da-baía, o maior porcentual de germinação ocorreu no subsolo nãoadubado.

Aos 90 dias, foram feitas as contagens das plantas, sendo a taxa de germinação total no ambiente sombreado de $59 \%$ e no ambiente a pleno sol, de 64,3\%. Não houve, portanto, diferença significativa na germinação das sementes entre os ambientes. Segundo Aguiar et al. (2003), a plasticidade é de grande importância ecológica, pois as sementes podem germinar em qualquer situação de luz em que se encontram. Esse resultado indica que as sementes das espécies em avaliação podem germinar tanto a pleno sol quanto em clareira ou em sub-bosque.

Os substratos adubados foram os que apresentaram o menor número de sementes germinadas, sendo o subsolo adubado o tratamento (T4) que apresentou o mais baixo porcentual de germinação. Portanto, notouse que a adubação, de alguma maneira, interferiu nas sementes, reduzindo a germinação.

A análise de variância d o número de indivíduos germinados do banco de sementes mostrou não haver diferença significativa entre os ambientes testados. A mesma análise avaliou os valores médios da porcentagem de germinação apresentada pelas espécies introduzidas, revelando não haver diferença significativa entre os ambientes na porcentagem de germinação das sementes de ipê-amarelo, ipê-preto, sibipiruna e jacarandáda-baía.

\subsection{Crescimento das mudas utilizadas no enriquecimento}

O solo orgânico adubado foi o melhor substrato para o crescimento em altura das mudas de sibipiruna, jacarandá-da-baía e ipê-preto. Nesse solo, ainda foram encontradas as maiores médias de crescimento em diâmetro das mudas de sibipiruna e das de ipê-preto, que cultivadas nesse substrato a pleno sol (T6)

Tabela 4 - Porcentagem de germinação das sementes de sibipiruna (SI), jacarandá-da-baía (JA), ipê-amarelo (IA) e ipêpreto (IP) nos diferentes tratamentos e o laboratório (L)

Table 4 - Percentage of germination of "sibipiruna"(SI), ”jacaranda-da-bahia” (JA), “ipê-amarelo" (IA), "ipê-preto" (IP) seeds under different treatments and laboratory test $(L)$

\begin{tabular}{|c|c|c|c|c|c|c|c|}
\hline SI & & $\mathrm{J}_{t}$ & & IA & & IP & \\
\hline Tratamentos & & Tratamentos & & Tratamentos & & Tratamentos & \\
\hline $\mathrm{L}$ & $73 \mathrm{a}$ & $\mathrm{L}$ & $71 \mathrm{a}$ & $\mathrm{L}$ & $90 \mathrm{a}$ & 5 & $87 \mathrm{ba}$ \\
\hline 7 & $63 \mathrm{ba}$ & 3 & $67 \mathrm{ba}$ & 5 & 86 a & $\mathrm{L}$ & $78 \mathrm{ba}$ \\
\hline 5 & $58 \mathrm{ba}$ & 1 & $55 \mathrm{cba}$ & 7 & $84 \mathrm{a}$ & 8 & $76 \mathrm{ba}$ \\
\hline 3 & $56 \mathrm{ba}$ & 2 & $53 \mathrm{cba}$ & 6 & $84 \mathrm{a}$ & 7 & $76 \mathrm{ba}$ \\
\hline 1 & $53 b$ & 6 & $48 \mathrm{cba}$ & 3 & $80 \mathrm{a}$ & 3 & $74 \mathrm{ba}$ \\
\hline 2 & $50 \mathrm{~b}$ & 5 & $46 \mathrm{cb}$ & 1 & 79 a & 1 & $73 \mathrm{ba}$ \\
\hline 6 & $50 b$ & 8 & $45 \mathrm{cb}$ & 8 & $75 \mathrm{ba}$ & 2 & $64 \mathrm{ba}$ \\
\hline 8 & $45 b$ & 7 & $42 c$ & 2 & $68 \mathrm{ba}$ & 6 & $64 \mathrm{ba}$ \\
\hline 4 & $44 b$ & 4 & $41 \mathrm{c}$ & 4 & $54 b$ & 4 & $48 b$ \\
\hline
\end{tabular}

Médias seguidas pela mesma letra não diferem entre si, a 5\% de probabilidade, pelo teste de Tukey.

R. Árvore, Viçosa-MG, v.31, n.6, p.1145-1154, 2007 
apresentaram o melhor resultado para essa variável. Essa resposta das mudas demonstra a preferência dessas espécies por solos adubados e ricos em matéria orgânica. Nesse substrato, o crescimento em altura foi maior que em diâmetro (Razão H/D), nas mudas de jacarandá-da-baía, ipê-preto e sibipiruna, sendo o crescimento das mudas em altura de sibipiruna maior que o crescimento em diâmetro no solo orgânico adubado a pleno sol (interação solo $\mathrm{x}$ ambiente). No solo adubado foram encontradas, ainda, as maiores médias de área foliar para ipê-preto e da razão de área foliar tanto para as mudas de ipê-preto quanto de ipê-amarelo (Tabela 5).

Segundo Benincasa (1998), a razão de área foliar expressa a área foliar útil para fotossíntese, sendo essa a razão entre área foliar e matéria seca total. Esse parâmetro declina à medida que a planta cresce, pois há aumento na interferência de folhas superiores sobre as inferiores, bem tendência da área foliar útil em diminuir a partir de certa fase do desenvolvimento.

As mudas de ipê-amarelo apresentaram os melhores resultados em solo orgânico não-adubado, com os maiores valores de crescimento em altura e em área foliar e maior biomassa seca da parte área, e, ainda, o crescimento em diâmetro foi maior na interação desse substrato com o ambiente a pleno sol (T5). O solo orgânico sem adubação proporcionou para as mudas de sibipiruna o maior ganho de biomassa seca total, apresentando, para a relação H/D do coleto, as maiores médias na interação entre este solo e o ambiente sombreado, que se refere ao T1 (Tabela 6).

No subsolo adubado, as mudas de jacarandá-dabaía apresentaram os melhores resultados das variáveis avaliadas, ressaltando-se que essa resposta das mudas pode estar relacionada com a preferência da espécie a solos argilosos e argilo-arenosos, com baixo teor de alumínio, característica que foi observada no subsolo utilizado (Tabela 1). Esse baixo teor de alumínio no subsolo, em relação ao orgânico, que apresentou valores mais elevados deste metal, favoreceu o crescimento das mudas. Foram encontradas nas mudas de sibipiruna as maiores médias de diâmetro do coleto, de peso e de matéria seca da parte aérea na interação entre o substrato e o ambiente a pleno sol (T8), bem com os maiores valores da relação do peso de matéria seca da parte aérea sobre a raiz.

Tabela 5 - Altura (H), diâmetro (D), relação altura/diâmetro do coleto (RH/D), área foliar (AF), peso de biomassa seca da parte aérea (BSPA), raiz (BSR), total (BST), relação da parte aérea/raiz (RPA/R) e razão área foliar sobre massa seca total (RAF) das mudas nos solos testados, após 90 dias

Table 5 - Height $(H)$, diameter $(D)$, ratio between diameter/height $(R H / D)$, leaf area $(L A)$, shoot dry biomass $(B S P A)$, root biomass $(B S R)$, total dry biomass $(B S T)$, ratio between root and shoot $(R P A / R)$ and leaf area ratio $(R A F)$ on total dry mass of seedlings in the soils tested, after 90 days

\begin{tabular}{|c|c|c|c|c|c|c|c|c|c|}
\hline \multicolumn{10}{|c|}{ Sibipiruna (Caesalpinia peltophoroides) } \\
\hline Solo & $\mathrm{H}$ & $\mathrm{D}$ & RH/D & $\mathrm{AF}$ & BSPA & BSR & BST & RPA/R & RAF \\
\hline 1 & $8,94 \quad \mathrm{a}$ & $3,25 \mathrm{cb}$ & $2,80 \mathrm{a}$ & & $0,71 \mathrm{a}$ & $0,32 \mathrm{a}$ & $1,03 \mathrm{a}$ & $2,31 \mathrm{ba}$ & \\
\hline 2 & 9,04 a & 3,49 ba & 2,71 a & & $0,77 \mathrm{a}$ & $0,35 \mathrm{a}$ & 1,12 a & $2,37 \mathrm{ba}$ & \\
\hline 3 & $6,13 \mathrm{c}$ & $2,99 \mathrm{c}$ & $2,08 \mathrm{~b}$ & & $0,44 \mathrm{~b}$ & $0,27 \mathrm{a}$ & $0,71 \mathrm{~b}$ & $1,87 \mathrm{~b}$ & \\
\hline 4 & $7,69 \mathrm{~b}$ & 3,74 a & $2,13 b$ & & $0,79 \mathrm{a}$ & $0,28 \mathrm{a}$ & $1,07 \mathrm{a}$ & 2,88 a & \\
\hline \multicolumn{10}{|c|}{ Jacarandá-da-baía (Dalbergia nigra) } \\
\hline 1 & 8,73 a & $2,09 \mathrm{a}$ & $4,63 \mathrm{a}$ & & $0,13 \mathrm{ba}$ & $0,10 \mathrm{ba}$ & $0,23 \mathrm{~b}$ & $1,33 \mathrm{a}$ & \\
\hline 2 & 9,42 a & $2,03 \mathrm{a}$ & $4,71 \mathrm{a}$ & & $0,13 \mathrm{ba}$ & $0,07 \mathrm{~b}$ & $0,21 \mathrm{~b}$ & $1,70 \mathrm{a}$ & \\
\hline 3 & $5,98 \mathrm{~b}$ & $1,71 \mathrm{a}$ & $3,53 b$ & & $0,10 \mathrm{~b}$ & $0,07 \mathrm{~b}$ & $0,18 \mathrm{~b}$ & $1,37 \mathrm{a}$ & \\
\hline 4 & $9,07 \mathrm{a}$ & $2,77 \mathrm{a}$ & $3,74 \mathrm{ba}$ & - & $0,20 \mathrm{a}$ & 0,12 a & 0,32 a & $1,71 \mathrm{a}$ & \\
\hline \multicolumn{10}{|c|}{ Ipê-amarelo (Tabebuia serratifolia) } \\
\hline 1 & 5,42 a & $1,95 \mathrm{a}$ & $2,89 \mathrm{a}$ & $24,87 \quad a$ & $0,18 \quad \mathrm{a}$ & $0,15 \mathrm{a}$ & $0,34 \mathrm{a}$ & $1,20 \mathrm{a}$ & $0,32 \mathrm{a}$ \\
\hline 2 & $5,04 \mathrm{a}$ & $1,94 \mathrm{a}$ & $2,69 \mathrm{a}$ & $23,51 \mathrm{ba}$ & 0,16 ba & $0,11 \mathrm{a}$ & $0,27 \mathrm{a}$ & $1,40 \mathrm{a}$ & $0,35 \mathrm{a}$ \\
\hline 3 & $3,16 \mathrm{~b}$ & $1,50 \mathrm{~b}$ & $2,08 \mathrm{~b}$ & $13,12 \mathrm{c}$ & $0,11 \mathrm{c}$ & $0,10 \mathrm{a}$ & $0,22 \mathrm{a}$ & $1,17 \mathrm{a}$ & $0,27 \mathrm{a}$ \\
\hline 4 & $3,50 \mathrm{~b}$ & $1,73 \mathrm{ba}$ & $2,14 \mathrm{~b}$ & $17,71 \mathrm{cb}$ & $0,14 \mathrm{cb}$ & $0,29 \mathrm{a}$ & $0,44 \mathrm{a}$ & $1,25 \mathrm{a}$ & $0,28 \mathrm{a}$ \\
\hline \multicolumn{10}{|c|}{ Ipê-preto (Zeyheria tuberculosa) } \\
\hline 1 & 6,47 a & 3,17 ba & $2,10 \mathrm{a}$ & 32,78 a & $0,38 \mathrm{a}$ & $0,18 \mathrm{a}$ & $0,57 \mathrm{a}$ & $2,14 \mathrm{a}$ & 55,66 a \\
\hline 2 & $6,70 \mathrm{a}$ & $3,27 \quad \mathrm{a}$ & $2,11 \mathrm{a}$ & 38,87 a & $0,37 \mathrm{a}$ & $0,18 \mathrm{a}$ & $0,55 \mathrm{a}$ & $2,13 \mathrm{a}$ & 69,26 a \\
\hline 3 & $4,15 b$ & $2,62 \mathrm{c}$ & $1,62 b$ & $13,95 b$ & $0,22 b$ & $0,13 \mathrm{a}$ & $0,56 \mathrm{a}$ & $1,83 \mathrm{a}$ & $39,46 b$ \\
\hline 4 & $4,63 b$ & $2,93 \mathrm{cb}$ & $1,59 \mathrm{~b}$ & $31,20 \mathrm{a}$ & 0,33 a & $0,23 \mathrm{a}$ & $0,35 \mathrm{a}$ & $2,43 a$ & 60,98 a \\
\hline
\end{tabular}

Médias seguidas pela mesma letra não diferem entre si, a 5\% de probabilidade, pelo teste de Tukey. 
Tabela 6 - Diâmetro (D), relação altura/diâmetro do coleto (RH/D), peso de biomassa seca da parte aérea (BSPA) e razão de área foliar (AF) das mudas, para o desdobramento dos solos dentro de cada ambiente (Interação)

Table 6-Diameter $(D)$, diameter/height ratio $(R H / D)$, shoot dry biomass weight (BSPA), and leaf area ratio( $A F)$ of seedlings for soil interaction inside each environment

\begin{tabular}{|c|c|c|c|c|c|c|c|c|}
\hline \multirow[b]{3}{*}{ Solo } & \multicolumn{8}{|c|}{ Sibipiruna (Caesalpinia peltophoroides) } \\
\hline & \multicolumn{2}{|c|}{$\mathrm{D}$} & \multicolumn{2}{|c|}{$\mathrm{RH} / \mathrm{D}$} & \multicolumn{2}{|c|}{ BSPA } & \multicolumn{2}{|c|}{ RAF } \\
\hline & Ambiente 1 & Ambiente 2 & Ambiente 1 & Ambiente 2 & Ambiente 1 & Ambiente 2 & Ambiente 1 & Ambiente 2 \\
\hline 1 & - & - & 3,19 a & $2,40 \mathrm{a}$ & $0,72 \mathrm{a}$ & $0,69 \mathrm{~b}$ & - & \\
\hline 2 & - & - & $2,96 \mathrm{a}$ & 2,47 a & 0,67 a & 0,86 ba & & \\
\hline 3 & & & $2,16 b$ & $2,00 \mathrm{~b}$ & $0,43 b$ & $0,45 \mathrm{c}$ & & \\
\hline \multirow[t]{2}{*}{4} & $\longrightarrow$ & $\longrightarrow$ & $2,34 \mathrm{~b}$ & $1,91 b$ & $0,64 \mathrm{ba}$ & 0,94 a & $\longrightarrow$ & - \\
\hline & \multicolumn{8}{|c|}{ Tabebuia serratifolia (ipê-amarelo) } \\
\hline 1 & $1,74 \mathrm{a}$ & $2,16 \mathrm{a}$ & 0,72 a & $0,69 \mathrm{~b}$ & $\longrightarrow$ & $\longrightarrow$ & 0,72 a & $0,69 \mathrm{~b}$ \\
\hline 2 & $1,76 \mathrm{a}$ & $2,13 \mathrm{a}$ & $0,67 \mathrm{a}$ & $0,86 \mathrm{ba}$ & - & $\longrightarrow$ & $0,67 \mathrm{a}$ & $0,86 \mathrm{ba}$ \\
\hline 3 & $1,50 \mathrm{a}$ & $1,49 b$ & $0,43 b$ & $0,45 \mathrm{c}$ & - & - & $0,43 b$ & $0,45 \mathrm{c}$ \\
\hline \multirow[t]{2}{*}{4} & $1,84 \mathrm{a}$ & $1,62 b$ & $0,64 \mathrm{ba}$ & 0,94 a & $\longrightarrow$ & E & $0,64 \mathrm{ba}$ & $0,94 \quad \mathrm{a}$ \\
\hline & \multicolumn{8}{|c|}{ Ipê-preto (Zeyheria tuberculosa) } \\
\hline 1 & $3,04 a$ & $3,30 \mathrm{a}$ & - & $\longrightarrow$ & - & - & - & - \\
\hline 2 & $3,07 \mathrm{a}$ & 3,47 a & & - & & 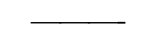 & _ & $\longrightarrow$ \\
\hline 3 & $2,68 \mathrm{a}$ & $2,56 b$ & - & $\longrightarrow$ & $\longrightarrow$ & . & 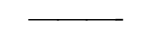 & - \\
\hline 4 & $3,11 \mathrm{a}$ & $2,75 b$ & $\longrightarrow$ & $\longrightarrow$ & $\longrightarrow$ & $\longrightarrow$ & - & - \\
\hline
\end{tabular}

Médias seguidas pela mesma letra não diferem entre si, a 5\% de probabilidade, pelo teste de Tukey.

Já o subsolo não-adubado apresentou, no geral, baixos resultados das variáveis de crescimento avaliadas (H, D, H/D, BSPA, BSR, BST, RPA/R, AF e RAF), nas mudas das espécies escolhidas para este estudo de enriquecimento de serapilheira.

A adubação proporcionou crescimento das plantas tanto de ipê-amarelo, ipê-preto, sibipiruna e jacarandáda-baía testados no enriquecimento quanto dos indivíduos arbóreos e herbáceos que emergiram do banco de sementes.

Quanto aos ambientes testados, o a pleno sol apresentou respostas significativas para as mudas de sibipiruna, nas variáveis de crescimento, com os maiores valores para o diâmetro do coleto e peso de matéria seca de raiz, favorecendo ainda a incorporação de biomassa seca. Muito embora as mudas dessa espécie não tenham apresentado diferença na análise estatística, realizada para crescimento em altura nos dois ambientes estudados, notou-se que os tamanhos das mudas sombreadas foram superiores ao àquelas cultivadas a pleno sol (Tabela 7). Aguiar et al. (2003), estudando os níveis de sombreamento adequados ao processo de germinação de sementes e à formação de mudas de Caesalpinia echinata (pau-brasil), observaram que as mudas apresentaram maior diâmetro do caule a pleno sol, em comparação com as plantas sob sombreamento de 60 e $80 \%$. Já a variável altura da planta não apresentou diferenças significativas estatisticamente entre os tratamentos. Fonseca et al. (2002) obtiveram resultados semelhantes ao estudar o comportamento de Trema micrantha (L.) Blume, sob diferentes níveis de sombreamento, observando decréscimo linear no diâmetro do colo da planta, em função do aumento do período sob sombreamento, elevação da altura e redução acentuada e posterior aumento no número de folhas das plantas.

No geral, as mudas de jacarandá-da-baía, ipê-amarelo e ipê-preto, cultivadas no ambiente sombreado, obtiveram maior crescimento em altura. A altura é um ótimo parâmetro, pois as espécies possuem diferentes padrões de respostas, de acordo com a sua capacidade adaptativa às variações de luz (MUROYA et al., 1997). As mudas de jacarandá apresentaram, ainda, as maiores médias de diâmetro do coleto e relação H/D. Tanto as mudas de ipê-amarelo quanto as de ipê-preto exibiram maiores médias de área foliar nesse ambiente.

O aumento da área foliar com o sombreamento é uma adaptação que permite ao vegetal aumentar rapidamente a superfície fotossintetizante e assegurar um aproveitamento maior da baixa intensidade luminosa (PEDROSO e VARELA, 1995). Com o aumento da área foliar, a planta mostra sua habilidade em utilizar a radiação fotossinteticamente ativa e alocar os fotoassimilados em resposta a um ambiente particular de luminosidade 
(DIAS FILHO, 1997). Assim, a área foliar pode ser considerada um índice de produtividade, dada à importância da folha, que é um órgão fotossintetizante na produção biológica.
As mudas provenientes das sementes utilizadas no enriquecimento e do banco de sementes tiveram maior crescimento no ambiente sombreado, o que demonstra que há diferença entre os ambientes testados.

Tabela 7 - Altura (H), diâmetro (D), relação altura/diâmetro do coleto (RH/D), área foliar (AF), peso de biomassa seca da parte aérea (BSPA), raiz (BSR), total (BST), relação da parte aérea/raiz (RPA/R) e razão área foliar sobre massa seca total (RAF) das mudas nos diferentes ambientes testados, obtidas aos 90 dias

Table 7 - Height $(H)$, diameter $(D)$, diameter/height ratio $(R H / D)$, leaf area $(A F)$, shoot dry biomass $(B S P A)$, root biomass $(B S R)$, total dry biomass (BST), root/ shoot ratio $(R P A / R)$ and leaf area/total dry mass ratio $(R A F)$ of seedlings in the environments tested, after 90 days

\begin{tabular}{|c|c|c|c|c|c|c|c|c|c|}
\hline \multicolumn{10}{|c|}{ Sibipiruna (Caesalpinia peltophoroides) } \\
\hline Solo & $\mathrm{H}$ & $\mathrm{D}$ & RH/D & $\mathrm{AF}$ & BSPA & BSR & BST & $\mathrm{RPA} / \mathrm{R}$ & RAF \\
\hline 1 & $8,15 \mathrm{a}$ & $3,10 b$ & $2,66 \mathrm{a}$ & - & $0,61 \mathrm{a}$ & $0,26 \mathrm{~b}$ & $0,88 \mathrm{a}$ & $2,45 \mathrm{a}$ & \\
\hline 2 & $7,75 \mathrm{a}$ & 3,63 a & $2,19 b$ & - & $0,73 \mathrm{a}$ & $0,35 \mathrm{a}$ & $1,08 \mathrm{a}$ & $2,26 a$ & \\
\hline \multicolumn{10}{|c|}{ Jacarandá-da-baía (Dalbergia nigra) } \\
\hline 1 & 9,13 a & $2,25 \mathrm{a}$ & $4,68 \mathrm{a}$ & $\longrightarrow$ & $0,15 \mathrm{a}$ & $0,08^{\mathrm{a}}$ & $0,24 \mathrm{a}$ & $1,81 \mathrm{a}$ & \\
\hline 2 & $7,48 \mathrm{~b}$ & $2,06 \mathrm{a}$ & $3,62 b$ & - & $0,13 \mathrm{a}$ & $0,11^{\mathrm{a}}$ & $0,23 \mathrm{a}$ & $1,25 b$ & \\
\hline \multicolumn{10}{|c|}{ Ipê-amarelo (Tabebuia serratifolia) } \\
\hline 1 & $4,62 \mathrm{a}$ & $1,70 b$ & 23,85 a & $2,72 \mathrm{a}$ & $014 a$ & $0,15^{\mathrm{a}}$ & $0,30 \mathrm{a}$ & $1,28 \mathrm{a}$ & $\overline{0,31^{\mathrm{a}}}$ \\
\hline 2 & $3,95 b$ & $1,85 \mathrm{a}$ & $15,76 b$ & $2,18 b$ & $0,15 \mathrm{a}$ & $0,17^{\mathrm{a}}$ & $0,32 \mathrm{a}$ & $1,23 \mathrm{a}$ & $0,30^{\mathrm{a}}$ \\
\hline \multicolumn{10}{|c|}{ Ipê-preto (Zeyheria tuberculosa) } \\
\hline 1 & $6,03 \mathrm{a}$ & $2,97 \mathrm{a}$ & $36,14 \mathrm{a}$ & $2,07 \mathrm{a}$ & $0,35 \mathrm{a}$ & $0,15^{\mathrm{a}}$ & $0,50 \mathrm{a}$ & $2,46 \mathrm{a}$ & $\overline{69,26 a}$ \\
\hline 2 & $4,94 \mathrm{~b}$ & $3,02 \mathrm{a}$ & $22,26 b$ & $1,64 b$ & $0,31 \mathrm{a}$ & $0,21^{\mathrm{a}}$ & $0,52 \mathrm{a}$ & $1,80 \mathrm{a}$ & $43,42 b$ \\
\hline
\end{tabular}

Médias seguidas pela mesma letra não diferem entre si, a $5 \%$ de probabilidade, pelo teste de Tukey.

\section{CONCLUSÃO}

Pode-se concluir que, enquanto os substratos nãoadubados foram os melhores para a germinação das sementes, a adubação realizada nos substratos contribuiu, por sua vez, para o crescimento das mudas das espécies utilizadas.

O ambiente sombreado favoreceu o crescimento das mudas, tanto das espécies oriundas do banco de sementes presentes na serapilheira e no solo orgânico quanto das utilizadas no enriquecimento.

Portanto, ficou evidenciada a eficiência do enriquecimento do banco de sementes, confirmando o potencial dessa técnica para a revegetação de áreas degradadas.

\section{AGRADECIMENTOS}

À CAPES pela bolsa de estudo e ao CNPq.

\section{REFERÊNCIAS}

AGUIAR, F. F. A. et al. Germinação de sementes e formação de mudas de Caesalpinia echinata Lam. (pau-brasil): efeito de sombreamento. Revista Árvore, v.29, n.6, p.871-875, 2005.
ARATO, H. D.; MARTINS, S. V.; FERRARI, S. H. S. Produção e decomposição de serapilheira em um sistema agroflorestal implantado para recuperação de área degradada em Viçosa-MG. Revista Árvore, v.27, p.715-721, 2003.

BENINCASA, M. M. P. Análise de crescimento de plantas: noções básicas. Jaboticabal: FUNEP, 1998. 42p.

CRONQUIST, A. An integrated system of classification of flowering plants. New York: Columbia University, 1981. 1262p.

DIAS FILHO, M. B. Physiological response of Solanum crinitum Lam. to contrasting light environments. Pesquisa Agropecuária Brasileira, v. 32, p.789-796, 1997.

FERREIRA, C. A G. et al. Reabilitação de áreas mineradas de bauxita no planalto de Poços de Caldas, MG. In: SIMPOSIO BRASILEIRO DE RECUPERAÇÃO DE ÁREAS DEGRADADAS, 3., 1997, Ouro Preto. Trabalhos voluntários... Viçosa, MG: SOBRADE/UFV-DPS/DEF, 1997. p.27-35. 
FERREIRA, D. F. Análises Estatísticas por meio do SISVAR para Windows versão 4.0 In: REUNIÃO BRASILEIRA DA SOCIEDADE INTERNACIONAL DE BIOMETRIA, 45., 2000, São Carlos. Programas e Resumos... São Carlos: Universidade Federal de São Carlos, 2000. p.235.

FONSECA, E. P. et al. Padrão de qualidade de mudas de Trema micrantha (L.) Blume, produzidas sob diferentes períodos de sombreamento. Revista Árvore, v.26, n.4, p.515-523, 2002.

FRANCO, B. K. S. Análise do banco de sementes e da regeneração natural em um trecho de floresta estacional semidecidual no campus da Universidade Federal de Viçosa, Viçosa, MG. 2005. $73 f$. Tese (Mestrado em Ciência Florestal) - Universidade Federal de Viçosa, Viçosa, MG, 2005.

GASPARINO, D. et al. Quantificação do banco de sementes sob diferentes usos do Solo em área de domínio ciliar. Revista Árvore, v.30, n.1, p.1-9, 2006.

GONÇALVES, J. L. M. Recomendação de adubação para Eucalyptus, Pinus e espécies típicas da Mata Atlântica. Documentos Florestais, v.15, p.1-23, 1995.

INSTITUTO BRASILEIRO DO MEIO AMBIENTE E DOS RECURSOS NATURAIS RENOVÁVEIS IBAMA. Manual de recuperação de áreas degradadas pela mineração: técnicas de revegetação. Brasília: 1990. 94p.

LABOURIAU, L.G. A germinação das sementes. Washington: Secretaria da OEA, 1983. 173p.

LABOURIAU, L. G.; VALADARES, M. E. B. On the germination of seed of Calotropis procera (Ait) Ait. F. Anais da Academia Brasileira de Ciências, v.48, n.2, p.236-284, 1976.

LEAL FILHO, N. Caracterização do banco de sementes de três estádios de uma sucessão vegetal na Zona da Mata de Minas Gerais. 1992. 116 f. Tese (Mestrado em Ciência Florestal) - Universidade Federal de Viçosa, Viçosa, MG, 1992.

R. Árvore, Viçosa-MG, v.31, n.6, p.1145-1154, 2007
MARANGON, L.; SOARES, J. J.; FELICIANO, A. L. P. Florística arbórea da Mata da Pedreira, município de Viçosa, Minas Gerais. Revista Árvore, v.27, n.2, p.207-215, 2003.

MUROYA, K.; VARELA, V. P.; CAMPOS, M. A. A. Analise de crescimento de mudas de jacareúba (calophyllum anglure - Guttiferae) cultivadas em condições de viveiro. Acta Amazônica, v.27, n.3, p.197-212, 1997.

OZÓRIO, T. F. Potencial de uso da serapilheira na recuperação de áreas degradadas por mineração de ferro, Mariana - MG. 2000. 62 f. (Mestrado em Ciência Florestal) - Universidade Federal de Viçosa, Viçosa, MG, 2000.

PEDROSO, S. G.; VARELA, V. P. Efeito do sombreamento no crescimento de mudas desumaúma (Ceiba pentandra (L.) Gaertn.). Revista Brasileira de Sementes, v.17, n.1, p.47-51, 1995.

REDENTE, E. F.; McLENDON, T.; DePUIT, E. J. Manipulation of vegetation community dynamics for degraded land rehabilitation. In: SIMPÓSIO BRASILEIRO DE PESQUISA FLORESTAL, 1., 1993, Belo Horizonte. Anais...Belo Horizonte: SIF, 1993. p.265-278.

SILVA, A. F.; SANTOS, E. R.; SOARES JÚNIOR. Levantamento florístico de um trecho de floresta estacional semidecidual na Zona da Mata, Viçosa - MG. In: ERBOT - ENCONTRO DE BOTÂNICA - Conservação, manejo e recuperação de bacias hidrográficas, 21., 1999, Vitória, ES. Resumo... Vitória: SSB/ SECCIONAL MG/ES, 1999. p.56.

SOUZA, P. A. et al. Avaliação do banco de sementes contido na serapilheira de um fragmento florestal visando recuperação de áreas degradadas Cerne, v.12, n.1, p.56-67, 2006. 